\title{
A Method of Improving Treatment with Esters.
}

E. S. R. Alfred.

$7 \mathrm{HE}$ prevailing method during the past three years of giving iodised esters was to give increasing doses twice weekly over a period of twenty weeks (or roughly five months), then intermitting for one month; this was followed by a further twenty weeks' treatment followed by a further four weeks' rest. In a straightforward case, the initial dose would thus be 1 c.c.; this was given once; then 2 c.c. twice, 3 c.c. four times, 4 c.c. four times, 5 c.c. six times and 6 c.c. for the rest of the course. After the interval, the initial close was 2 c.c.; this was given twice, then 3 c.c. four times and so on as in the first course. Every suitable case was put on esters and the treatment was pushed. It was common experience to find lepra reaction setting in if specific treatment with esters was pushed to any undue extent. It was also commonly found in other cases that a patient remained well so long as he remained on esters injections, and that as soon as a rest was ordered signs of activity and/or reaction cropped up.

From my observations on the result of fluorescein treatment as instituted by Dr. G. A. Ryrie at Sungei Buloh (part of which was published in the International Journal of Leprosy, Vol. 2, No. 2, April 1934), I was of opinion that 
fluorescein has a definite place in the armamentaria against lepra reaction. A few cases were therefore put on fluorescein injections during the rest or interval obtaining at the end of 1933. These were all cases that had been activated or were definitely showing signs of a mild lepra reaction as a result of esters medication. The solution of fluorescein was freshly prepared for each occasion with distilled water, sterilised by boiling and filtered. An obvious improvement was noticed as a result of fluorescein treatment. The use of this drug was extended in the June "interval " of 1934, and in addition, phthalic acid was exhibited for a collateral group of cases-a total of 173 cases being put on both drugs. Owing to shortage of drug, the majority of the cases so tried were similar to those mentioned above; only a comparatively small number was put on as a sort of control for the above. The results were again definitely satisfactory. The conclusions tentatively come to were that this treatment prevented the onset of reaction in a number of cases, or at least prevented a reaction from becoming worse, but accelerated recovery; and that this method of combining esters medication together with an "interval " treatment with fluorescein gave better results from the patient's general health point of view than esters medication alone. Also that fluorescein was the easier drug to use. Parenthetically, to the query as to why mild reaction need be treated at all, it may here be answered that the great majority of the patients at Sungei Buloh are Chinese, and that the reaction seen in them here is of a comparatively severe and intractable type.

It was therefore decided to try this "interval " treatment on a still larger scale and as a routine measure in December 1934. Thus 339 cases were so treated-310 with fluorescein and 29 with phthalic acid. The treatment consisted of four to six injections of a $2 \%$ solution of fluorescein given in 10 to 20 c.c. doses twice weekly, or four to six injections of a $1 \%$ solution of phthalic acid given in 10 c.c. doses twice weekly. The results assessed at the end of the year were as follow :-

\begin{tabular}{r|c|c|c|c|c}
\hline & $\begin{array}{c}\text { Total } \\
\text { treated }\end{array}$ & $\begin{array}{c}\text { Much } \\
\text { improved }\end{array}$ & Improved & Stationary & Worse \\
\hline Fluorescein.. & 310 & 14 & 247 & 35 & 14 \\
Phthalic acid ... & 29 & - & 15 & 8 & 6 \\
\hline Total & 339 & 14 & 262 & 43 & 20 \\
\hline
\end{tabular}


Comparative figures of cases on esters injections, etc. for 1933 and 1934 follow :-

\begin{tabular}{|c|c|c|c|}
\hline & 1933 & 1934 & $\begin{array}{l}\text { Increase for } 1934 \\
\text { expressed as a \% of } 1933\end{array}$ \\
\hline $\begin{array}{l}\text { Number of cases on esters injections } \\
\text { Number of esters injections given } \ldots \\
\text { Number of reactions severe enough to be } \\
\text { treated in Hospital } \ldots\end{array}$ & $\begin{array}{r}671 \\
24374 \\
197\end{array}$ & $\begin{array}{r}1289 \\
44452 \\
321\end{array}$ & $\begin{array}{l}92 \% \\
82 \% \\
63 \%\end{array}$ \\
\hline
\end{tabular}

The type of case treated in 1933 was generally of a better physique than that in 1934; that is, the 1,289 cases of 1934 include practically every one in the Settlement except the decrepit and senile cases and the groups on experimental treatments, whereas the 671 cases of 1933 included only those of better physique-there was then a larger number of cases on Tai Foong Chi and other or no treatment.

That the increase in the number of severe reactions $(63 \%)$ has not been more, but has remained in proportion to the increase in the number of cases treated $(92 \%)$ and the increase in the number of injections given (82\%), I attribute if not entirely at least in great part to the institution of this " interval " treatment. The above are not infallible criteria, but under the circumstances the best available.

The following tentative conclusions may be made :-

1. Better results are obtained when esters are exhibited and followed by an " interval " treatment with fluorescein, than when esters are used alone.

2. Reaction can be averted by the use of fluorescein after a period of esters medication. That is to say, " interval " treatment may be considered a sort of prophylactic treatment for lepra reaction.

3. This may be due to fluorescein raising the treatmenttolerance level of the tissues for esters.

4. Needless to say, previous conclusions drawn on fluorescein medication hold good; viz:-

$a$ results may vary according to the brand of fluorescein used;

$b$ the solution must be freshly made, sterilised by boiling and filtered;

$c$ fluorescein is the easier drug to use in a large series of cases than phthalic acid. 